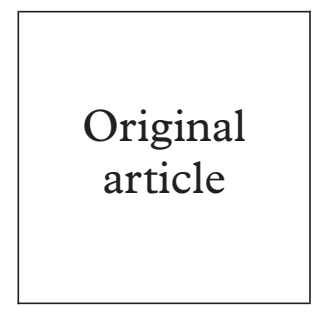

\title{
Prevalence of herpes simplex type 2 and syphilis serology among young adults in a rural Gambian community
}

\author{
Matthew Shaw, Marianne van der Sande, Beryl West, Katie Paine, Seihou Ceesay,
} Robin Bailey, Gijs Walraven, Linda Morison, Keith McAdam

\begin{abstract}
Objectives: To estimate prevalence and risk factors for herpes simplex 2 (HSV2) positivity, syphilis and Chlamydia trachomatis infection among rural people aged 15-34 in the Gambia.

Methods: Questionnaires and serum samples were collected from 1076 men and women aged 15-34 during a cross sectional prevalence survey in a rural area of the Gambia. Sera were screened for antibodies to herpes simplex virus type 2 (HSV2), and for syphilis using Treponema pallidum haemagglutination assay (TPHA) and rapid plasma reagin (RPR) tests. Urine was tested by polymerase chain reaction (PCR) for $C$ trachomatis infection.

Results: $28 \%$ of women and 5\% of men were HSV2 ELISA positive; $10 \%$ of women and $2 \%$ of men were TPHA positive; and $7 \%$ of women and $1 \%$ of men were both RPR and TPHA positive. Out of 1030 urine sample tested only six were positive for $C$ trachomatis. $7 \%$ of those who reported never having sex were positive for one or other of these tests. Prevalences of all STIs increased with age and were higher in women than men. Women were much less likely than men to seek treatment for STI symptoms at a health centre. Married people were at increased risk of an STI compared with single people. Jola and Fula women had a higher prevalence of HSV2 than women from other ethnic groups, and Fulas also had a higher prevalence of RPR/TPHA positivity. The limited number of sexual behaviour questions were not significantly associated with STIs after adjustment for age, marital status, and ethnic group.

Conclusions: The prevalences of the ulcerative infections HSV2 and syphilis in this population are a cause for concern. In a setting where HIV1 prevalence remains low this indicates an urgent need for STI control and behaviour change programmes to prevent an HIV epidemic. Concerns about the validity of reported sexual behaviour data high light the necessity of biological markers in the evaluation of behaviour change programmes.

(Sex Transm Inf 2001;77:358-365)
\end{abstract}

Keywords: seroepidemiological studies; Africa; herpes simplex virus

\section{Introduction}

HIV/AIDS is one of the most serious threats to the lives of people living in sub-Saharan Africa. ${ }^{1}$ To date the HIV epidemic has mainly affected eastern and southern Africa. The slower growth of the epidemic in west Africa is not well understood although widespread male circumcision $^{2}$ has been suggested as a possible factor. However, recently, alarming antenatal prevalences have been recorded in several west African states, such as Cote D'Ivoire (10\%), Cameroon ( $7 \%$ ), and Nigeria (5\%). Interventions need to be developed and implemented at this early stage, when they will be most effective at preventing the epidemic. ${ }^{4}$

Pending the development of a safe and effective vaccine against HIV, promoting behaviour change to safer sex (in the general population, as well as core groups), and controlling sexually transmitted infections (STIs) ${ }^{5}$ remain important strategies. Prevention programmes need to be developed, tested, and monitored for impact country by country. HIV incidence is the ideal primary outcome measure, but its use to evaluate the impact of interventions in low prevalence settings may be precluded by the enormous sample sizes required. Questionnaire data (for example, Behavioural Sentinel
Surveillance ${ }^{6}$ can be used to monitor behavioural change, but its validity can be questionable, ${ }^{7}$ especially if collected in an impersonal setting such as a community survey using structured interviews. ${ }^{8}$ In the Gambia, considerable stigma ${ }^{9}$ is attached to premarital and extramarital relationships, so that asking about this kind of behaviour is frequently unproductive, especially with women. ${ }^{10}$

Evidence of infection with other STIs may complement behaviour data or provide useful alternative markers to HIV. ${ }^{11}$ Not only is the principal route of infection the same as HIV, but their importance as co-factors in HIV transmission is significant, especially at the early stages in an epidemic. ${ }^{12}$ Seropositivity for syphilis (RPR/TPHA) and for herpes simplex type 2 (HSV2) has been found to be associated with number of lifetime partners, prevalent HIV infection, ${ }^{13}{ }^{14}$ and with HIV seroconversion. ${ }^{15} 16$ Therefore, since HSV2 is an opportunistic infection in AIDS, HIV1 and HSV2 may cause mutually reinforcing epidemics, ${ }^{16}$ although little research has been conducted on this in an area where HIV2 is common.

The prevalence of HIV in the Gambia is relatively low, ${ }^{17}$ and HIV2 makes up a substantial proportion of infections. ${ }^{18}$ The highest antenatal HIV prevalences have been found in 
some rural areas, especially in the Western Division, where prevalences of active syphilis (by RPR/TPHA) and HSV2 among antenatal women were also above average compared with the rest of the country (O'Donovan D, unpublished rapid assessment, 1995). One reason suggested for this is the opportunity to meet new sexual partners at the annual circumcision/initiation ceremonies of the Jola ethnic group, which are attended by many thousands of clan members from around the region (Enel C, unpublished fieldwork report 1995). Most men and women are circumcised in the Gambia (for women this usually involves removal of the clitoris and labia minora).${ }^{19}$ The study described in this paper was conducted in this relatively high STI prevalence area as part of a series of studies to assess the feasibility of evaluating a behavioural intervention (Stepping Stones-Gambia $)^{20}$ in a proposed community randomised trial. This intervention works with entire villages and aims to reduce vulnerability to STI/HIV by promoting dialogue about these problems across the community.

Data on STIs from representative community surveys of rural areas in the developing world are rare. ${ }^{21}$ These data are essential to policymakers who need to make decisions about STI control policies and monitor their impact. Therefore, the aims of this paper are to give estimates of the prevalence of HSV2, syphilis, and Chlamydia trachomatis infection in a rural area of west Africa and to identify those people at most risk of acquiring them.

\section{Methods}

The study area in The Western Division of the Gambia contains 37000 people mainly of the Jola, Mandinka, and Fula ethnic groups, 58\% of whom live in settlements of less than 500 people. The survey was conducted between September and December 1998, between the rainy season and Ramadan (during which time interviews about sexual behaviour are unacceptable).

Sample size was calculated using data from an earlier study of antenatal women (O'Donovan D, unpublished rapid assessment, 1995), in the same area. A sample size of 1600 subjects aged 15-34 was calculated to provide sufficiently narrow confidence intervals within 2 year age bands for prevalence estimates allowing for up to $20 \%$ non-participation.

The intervention had been developed for community members of villages with populations of 200-500 people. Only villages that were considered suitable for the intervention were considered eligible for the study. Twenty six villages were suitable, from which 17 were randomly selected for the study. A district meeting was held to sensitise village headmen, followed by meetings in each village where the study was explained to residents. Following consent from each village, the population over 10 years was enumerated, using an event calendar to ascertain age where necessary. All people aged 15-34 were invited to participate if they had been resident in the village for 6 months in the previous year and had not travelled out of the area at the time of the survey.
Informed consent was required from the individuals before they could participate in the study (and from the guardian of participants under the age of 18). The Gambia Government-MRC joint ethics committee approved the study procedures.

A questionnaire consisting of sociodemographic and sexual behaviour questions was administered in private by a same sex interviewer. For reasons of acceptability this included only indirect questions about premarital sex, and respondents were not asked about the number of sexual partners they had had either recently or in their lifetime. The responses to questions on pregnancy, marital status, and sex in unmarried respondents were used to estimate how many participants had ever had sex. Premenarchal girls were not asked any sexual behaviour questions.

Participants were asked to provide a $5 \mathrm{ml}$ venous blood sample and a urine sample after they had held their urine for at least 2 hours. The samples were kept at $4^{\circ} \mathrm{C}$ and transported to the main laboratory 2 hours away where serum was separated and samples stored at $-70^{\circ} \mathrm{C}$. The urine was tested for $C$ trachomatis using an established in-house polymerase chain reaction (PCR) targeting the common cryptic plasmid, as described previously. ${ }^{22}$ Briefly, $1 \mathrm{ml}$ of urine was washed twice in TRIS/ $\mathrm{HCl}$ buffer and resuspended in $20 \mu \mathrm{l}$ of a suspension containing $0.5 \%$ Tween $20,0.5 \% \mathrm{v} / \mathrm{v}$ Igepal, and $100 \mu \mathrm{g} / \mathrm{ml}$ proteinase $\mathrm{K}$. The suspension was incubated at $60^{\circ} \mathrm{C}$ for 1 hour and then boiled for 10 minutes to inactivate the proteinase $\mathrm{K}$. A phenol/chloroform extraction was then carried out. Crude DNA preparations were stored at $-70^{\circ} \mathrm{C}$ until used, $5 \mu 1$ was used for each PCR reaction. A band on agarose gel corresponding to $370 \mathrm{bp}$ constituted a positive result. A suspension of chlamydial elementary bodies was tested in each run as a positive control.

Serum was tested for syphilis using RPR (Launch Diagnostics, UK) without titration, followed by TPHA (Microsyph-TP200, Launch Diagnostics UK). A positive TPHA test with negative RPR was interpreted as evidence of a previous, resolved infection with syphilis. A positive TPHA and RPR was interpreted as recent or untreated syphilis. Sera were tested for HSV2 using the peptide 55 ELISA $^{23}$ test, developed by the MRC Virology Unit. All the tests described above have been used elsewhere in the Gambia. ${ }^{17}$

Participants reporting STI symptoms received immediate syndromic treatment according to the WHO protocol. ${ }^{24}$ Subjects subsequently found to have untreated active syphilis or $C$ trachomatis infection were actively followed up, counselled, and offered free treatment. Partner treatment or, where preferred, partner notification slips enabling free treatment at the local health centre, were offered.

Data were double entered using EPI-INFO 6 and analysed using staTA 6 (Statacorp, Texas USA). Confidence intervals for prevalences were calculated taking account of the cluster sampling strategy used. Risk factors for HSV2, TPHA, and recent untreated syphilis were examined for men and women separately. The 
Table 1 Comparison of characteristics of eligible population and participants

\begin{tabular}{lllll}
\hline & Eligible & Refused/ not found & Questionnaire completed & Serum sample collected \\
\hline No & $1419(100 \%)$ & $172(12.1 \%)$ & $1247(87.9 \%)$ & $1078(76.0 \%)$ \\
Mean age & 22.8 & 24.0 & 22.7 & 22.8 \\
\% male & 42.8 & 42.4 & 42.9 & 42.5 \\
\% age & $1410(100 \%)$ & $164(11.6 \%)$ & $1247(87.9 \%)$ & $1078(76.0 \%)$ \\
$15-19$ & 33.2 & 28.1 & 35.4 & 34.1 \\
$20-24$ & 24.7 & 22.0 & 24.9 & 26.2 \\
$25-30$ & 22.7 & 23.8 & 22.4 & 17.5 \\
30-34 & 19.4 & 26.2 & 17.3 & 100 \\
& 100 & 100 & 100 & $1078(76.0 \%)$ \\
\% ethnicity & $1419(100 \%)$ & $172(12.1 \%)$ & $1247(87.9 \%)$ & 63.7 \\
Jola & 63.9 & 72.7 & 62.6 & 16.0 \\
Mandinka & 15.4 & 9.9 & 16.2 & 7.7 \\
Fula & 8.2 & 10.5 & 7.9 & 12.6 \\
Others & 12.5 & 7.0 & 13.3 & 100 \\
& 100 & 100 & 100 & \\
\hline
\end{tabular}

laboratory results were cross tabulated with sociodemographic and sexual behaviour characteristics and $\chi^{2}$ tests or Fisher's exact tests of association were performed as appropriate. Logistic regression models were fitted to examine the effect of risk factors adjusted for possible confounders for those STIs with sufficient numbers of positive cases. For each model sociodemographic risk factors (age, ethnicity, marital status, place of birth, village of residence) were entered first. Age, marital status, and ethnic group were always retained in the model because of their potential to confound other associations, as well as being potentially important risk factors in their own right. Other factors which did not significantly contribute to the model ( $p>0.05)$ were excluded. Factors thought to have the potential to influence risk behaviour (for example, migration, education, attendance at an initiation ceremony) were then entered and those contributing significantly to the model retained. Finally, a similar procedure was applied to the sexual behaviour risk factors (for example, early sex, sex before marriage, sex in the past month, ever used condoms, ever fathered a pregnancy or been pregnant, ever had symptom of STI).

\section{Results}

Eighty eight per cent of the eligible population were interviewed and $76 \%$ provided samples (see table 1). Women from the Jola and Fula ethnic groups $(15 \%, 86 / 567)$ were more likely to refuse or not to be found than women from the other ethnic groups $(5 \%, 13 / 244)$.

Table 2 Sociodemographic characteristics of participants

\begin{tabular}{|c|c|c|c|c|}
\hline & \multicolumn{2}{|c|}{ Men } & \multicolumn{2}{|c|}{ Women } \\
\hline & No & $\%$ & No & $\%$ \\
\hline \multicolumn{5}{|l|}{ Age } \\
\hline $15-19$ & 236 & 44 & 205 & 29 \\
\hline $20-24$ & 129 & 24 & 181 & 25 \\
\hline $25-29$ & 94 & 18 & 185 & 26 \\
\hline $30-34$ & 75 & 14 & 741 & 20 \\
\hline \multicolumn{5}{|l|}{ Marital status } \\
\hline Single & 432 & 81 & 174 & 24 \\
\hline 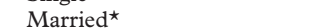 & 98 & 18 & 521 & 73 \\
\hline Monogamous marriage & & - & 235 & 33 \\
\hline Polygynous marriage & & - & 286 & 40 \\
\hline Separated/divorced/widowed & 3 & 1 & 17 & 2 \\
\hline \multicolumn{5}{|l|}{ Education } \\
\hline None & 65 & 12 & 410 & 58 \\
\hline Koranic education & 134 & 35 & 134 & 19 \\
\hline Some formal education & 282 & 53 & 168 & 24 \\
\hline
\end{tabular}

${ }^{\star}$ Men were not asked about number of wives.
Table 2 shows the sociodemographic characteristics for the men and women who participated in the survey. Although a high proportion of the men (44\%) were aged 15-19 this reflects the age pattern among all the men eligible for the study $(43 \%)$. The proportion of men and women with formal education was much higher in the 15-19 age group (45\% women and $65 \%$ men) than in older age groups, $27 \%$ of men and $10 \%$ of women were still at school at the time of the survey. In keeping with an area where the polygynous system is the norm, more than half of the married women were in polygynous marriages. Men tended to marry at an older age than women with the median age of marriage in this sample of young adults being 25 for men (interquartile range 21-27), and 17 for women (interquartile range 15-20). Most participants were from the Jola ethnic group (64\%) and born in the Gambia (89\%).

Male and female circumcision were almost universal in the study population with $96 \%$ of men and $98 \%$ of women reporting being circumcised. Nearly all women (97\%) had been through the initiation ceremony (a rite of passage) while only $66 \%$ of men reported being initiated. $53 \%$ of men and $48 \%$ of women had attended an initiation ceremony in the previous year.

\section{SEXUAL BEHAVIOUR}

Response rates for the questions on sexual behaviour were good ( $99 \%$ or more), except for questions concerning age at sexual debut and age of spouse. Women were more likely to give an age of sexual debut than men $(\mathrm{p}<0.05)$, with $78 \%(445 / 570)$ of the eligible women and $71 \%$ (229/323) of the eligible men answering the question. Unmarried women, however, were much less likely to give an answer compared with married women $(\mathrm{p}<0.01)$. Of those who didn't answer the majority response (213/219) was "don't know."

We estimated the proportion of the sample who had ever had sex by adding (i) the number of women who reported having been pregnant and men who reported fathering a pregnancy to (ii) those who were married and (iii) those unmarried people who reported having sex. Premenarchal women were assumed never to have had sex. This suggested that $60 \%$ $(322 / 534)$ of men and $85 \%(569 / 672)$ of women had had sex. Of the unmarried participants $51 \%$ of men and $20 \%$ of women were 
Table 3 Sexual behaviour

\begin{tabular}{|c|c|c|c|c|}
\hline & \multicolumn{2}{|l|}{ Men } & \multicolumn{2}{|l|}{ Women } \\
\hline & No & $\%$ & No & $\%$ \\
\hline \multicolumn{5}{|l|}{ Single participants } \\
\hline Report age at 1 st sex $\leqslant 15$ & $28 / 374$ & 7 & $3 / 160$ & 2 \\
\hline Ever had sex & $220 / 432$ & 51 & $34 / 174$ & 20 \\
\hline Had sex past month & $31 / 432$ & 7 & $6 / 173$ & 3 \\
\hline Ever used condom & $101 / 432$ & 23 & $12 / 173$ & 7 \\
\hline Fathered pregnancy $(M)$, been pregnant $(F)$ & $12 / 432$ & 3 & $16 / 135$ & 12 \\
\hline \multicolumn{5}{|l|}{ Currently married participants } \\
\hline Report age at 1 st sex $\leqslant 15$ & $5 / 65$ & 8 & $20 / 415$ & 5 \\
\hline Sex before marriage & $45 / 98$ & 46 & $42 / 519$ & 8 \\
\hline Had sex past month & $62 / 98$ & 63 & $363 / 518$ & 70 \\
\hline Have used condom & $25 / 98$ & 26 & $17 / 520$ & 3 \\
\hline Fathered pregnancy $(\mathrm{M})$ been pregnant $(\mathrm{F})$ & $87 / 98$ & 89 & $479 / 520$ & 92 \\
\hline \multicolumn{5}{|l|}{ Separated, widowed or divorced participants } \\
\hline Had sex past month & $0 / 3$ & 0 & $5 / 17$ & 29 \\
\hline
\end{tabular}

Table 4 Prevalence of STIs and STI symptoms

\begin{tabular}{|c|c|c|c|c|c|c|}
\hline & \multicolumn{3}{|l|}{ Men } & \multicolumn{3}{|l|}{ Women } \\
\hline & $r / n$ & $\%$ & $95 \% C I^{*}$ & $r / n$ & $\%$ & $95 \% C I^{*}$ \\
\hline$C$ trachomatis & $1 / 420$ & 0.2 & $(0,1.3)$ & $5 / 610$ & 0.8 & $(0.3,1.9)$ \\
\hline $\mathrm{RPR} / \mathrm{TPHA} \dagger$ & $6 / 457$ & 1.3 & $(0.1,2.5)$ & $42 / 612$ & 6.9 & $(2.7,11.0)$ \\
\hline TPHA $\dagger$ & $10 / 457$ & 2.2 & $(0.6,3.7)$ & $59 / 605$ & 9.7 & $(4.6,14.6)$ \\
\hline HSV2 $t$ & $22 / 432$ & 5.1 & $(3.2,7.6)$ & $164 / 575$ & 28.5 & $(21.4,35.6)$ \\
\hline Ever had STI symptom & $201 / 529$ & 38 & $(32.6,43.5)$ & $168 / 709$ & 23.7 & $(18.6,28.8)$ \\
\hline Ever had genital ulcer & $76 / 532$ & 14.3 & $(9.6,19.0)$ & $60 / 710$ & 8.4 & $(6.5,10.7)$ \\
\hline
\end{tabular}

*Adjusted for cluster sampling scheme used.

†Indeterminate results excluded.

estimated to have had sex. Unmarried men were more likely to report sex before the age of $15(7 \%)$ than women $(2 \%)$. The extent of premarital sex was estimated by adding (i) those who gave a child's age as higher than the duration of their marriage to (ii) those who gave an age of sexual debut lower than their age of marriage and (iii) those who were not married but reported having sex. Men were significantly more likely to report premarital sex than women $(p<0.001)$. Details of sexual behaviour variables by marital status are shown for men and women in table 3.

In this study $5 \%(2 / 37)$ of premenarchal girls who were not asked about sexual activity tested positive for HSV2. Seven per cent (19/278) of those men and women who reported being virgins tested positive for at least one laboratory test (HSV2, TPHA, or CT).

PREVALENCE AND RISK FACTORS FOR INFECTION The prevalence of $C$ trachomatis, recent or untreated syphilis, positive TPHA, and positive HSV2 are shown separately for men and women in table 4. Risk factors for each STI are shown in tables 5-7. Only one man and five women tested positive for $C$ trachomatis none of whom reported having symptoms of sexually transmitted infection.

The prevalence of recent or untreated syphilis was higher in women than men and increased with age (fig 1). The lower number of cases among the men meant that it was only possible to use logistic regression to adjust for possible confounders for the women. For the men (univariate analysis) married men, those with no formal education, and those from the Fula ethnic group were at significantly higher risk of recent or untreated syphilis (Table 5). The prevalence of recent or untreated syphilis was also higher in men who reported sex in the past month and those who reported fathering a pregnancy. The picture was similar for the women. Married women had a significantly higher prevalence of recent or untreated syphilis than single women, but there was little difference between those in monogamous and polygamous marriages. Mandinkas had a significantly lower and Fulas a significantly

Table 5 Risk factors for recent or untreated syphilis *

\begin{tabular}{|c|c|c|c|c|c|c|c|c|}
\hline \multirow[b]{2}{*}{ Risk factor } & & \multicolumn{3}{|l|}{ Men } & \multicolumn{3}{|l|}{ Women } & \multirow[b]{2}{*}{$\begin{array}{l}\text { Adjusted OR }(95 \% \\
C I) \neq\end{array}$} \\
\hline & & Positive/total & $\%$ positive & $\begin{array}{l}\text { Crude OR }(95 \% \\
\text { CI)t }\end{array}$ & Positive/total & $\%$ positive & Crude OR $(95 \% \mathrm{CI})$ & \\
\hline \multicolumn{9}{|l|}{ Age } \\
\hline $15-19$ & & $0 / 198$ & 0 & & $2 / 169$ & 1.2 & 1 & 1 \\
\hline $20-24$ & & $2 / 119$ & 1.7 & 1 & $8 / 163$ & 4.9 & $4.31(0.9,20.6)$ & $2.17(0.36,1.03)$ \\
\hline $25-29$ & & $2 / 76$ & 2.6 & $1.60(0.22,11.6)$ & $16 / 164$ & 9.8 & $9.21(2.08,40.74)$ & $3.77(0.65,21.82)$ \\
\hline $30-34$ & & $2 / 64$ & 3.1 & $1.89(0.26,13.72)$ & $16 / 124$ & 12.9 & $12.97(2.92,57.57)$ & $5.76(0.98,33.85)$ \\
\hline \multicolumn{9}{|l|}{ Marital status } \\
\hline Monogamous & \} & & & & $17 / 205$ & 8.3 & 1 & 1 \\
\hline Polygamous & \} & $4 / 83$ & 4.8 & 1 & $24 / 248$ & 9.7 & $1.18(0.62,2.27)$ & $1.12(0.57,2.2)$ \\
\hline Single & & $2 / 371$ & 0.5 & $0.11(0.02,0.59)$ & $1 / 142$ & 0.7 & $0.08(0.1,0.60)$ & 0 \\
\hline Div/wid & & $0 / 2$ & 0 & 0 & $0 / 17$ & 0 & 0 & $0.26(0.02,2.84)$ \\
\hline \multicolumn{9}{|l|}{ Ethnic group } \\
\hline Jola & & $4 / 313$ & 1.3 & 1 & $33 / 370$ & 8.9 & 1 & 1 \\
\hline Mandinka & & $0 / 71$ & 0 & 0 & $2 / 100$ & 2.0 & $0.23(0.05,0.98)$ & $0.28(0.06,1.19)$ \\
\hline Fula & & $1 / 31$ & 3.2 & $2.57(0.28,23.78)$ & $8 / 50$ & 16.0 & $2.16(0.93,5.02)$ & $2.36(0.97,5.72)$ \\
\hline Other & & $1 / 42$ & 2.4 & $1.88(0.21,17.27)$ & $2 / 92$ & 2.2 & $0.25(0.06,1.07)$ & $0.32(0.07,1.4)$ \\
\hline \multicolumn{9}{|l|}{ Education } \\
\hline None & & $1 / 58$ & 1.7 & 1 & $33 / 349$ & 9.4 & 1 & \\
\hline Islamic & & $5 / 167$ & 3.0 & $1.76(0.2,15.4)$ & $4 / 124$ & 3.2 & $0.32(0.11,0.92)$ & \\
\hline Formal & & $0 / 231$ & 0 & 0 & $5 / 139$ & 3.6 & $0.36(0.14,0.94)$ & \\
\hline \multicolumn{9}{|l|}{ Still in school } \\
\hline No & & $6 / 293$ & 2.0 & 1 & $41 / 531$ & 7.7 & 1 & \\
\hline Yes & & $0 / 164$ & 0 & 0 & $1 / 81$ & 1.2 & $0.15(0.02,1.1)$ & \\
\hline \multicolumn{9}{|c|}{ Fathered pregnancy $(M)$, or been pregnant $(F)$} \\
\hline No & & $2 / 374$ & 0.5 & 1 & $5 / 135$ & 3.7 & 1 & \\
\hline Yes & & $4 / 82$ & 4.9 & $9.54(1.72,53.00)$ & $36 / 445$ & 8.1 & $2.29(0.88,5.95)$ & \\
\hline \multicolumn{9}{|c|}{ 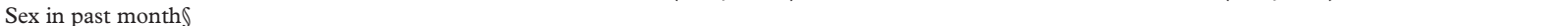 } \\
\hline No & & $2 / 200$ & 1 & 1 & $8 / 168$ & 4.8 & 1 & \\
\hline Yes & & $3 / 80$ & 3.75 & $3.86(0.96 .33 .69)$ & $34 / 334$ & 10.2 & $2.27(0.98,5.45)$ & \\
\hline
\end{tabular}

$\star$ Only those variables that were significant $(\mathrm{p}<0.05)$ for one or other of the sexes are shown.

+Because of the lower number of infections among men it was only possible to fit a logistic regression model for women.

$\ddagger$ Adjusted for the other two variables that were included in the final model.

§Participants who had had sex. 
Table 6 Risk factors for TPHA positivity *

\begin{tabular}{|c|c|c|c|c|c|c|c|c|}
\hline \multirow[b]{2}{*}{ Risk factor } & & \multicolumn{3}{|l|}{ Men } & \multicolumn{3}{|l|}{ Women } & \multirow[b]{2}{*}{$\begin{array}{l}\text { Adjusted OR }(95 \% \\
\text { CI } \neq\end{array}$} \\
\hline & & Positive/total & $\%$ positive & $\begin{array}{l}\text { Crude OR }(95 \% \\
\text { CI)t }\end{array}$ & Positive/total & $\%$ positive & $\begin{array}{l}\text { Crude OR }(95 \% \\
\text { CI) }\end{array}$ & \\
\hline \multicolumn{9}{|l|}{ Age } \\
\hline $15-19$ & & $0 / 197$ & 0.0 & 0 & $3 / 167$ & 1.8 & 1 & 1 \\
\hline $20-24$ & & $3 / 119$ & 2.5 & 1 & $11 / 161$ & 6.8 & $4.01(1.1,14.65)$ & $2.2(0.51,9.51)$ \\
\hline $25-29$ & & $3 / 76$ & 4.0 & $1.59(0.25,10.18)$ & $22 / 157$ & 14.0 & $8.91(2.61,30.41)$ & $4.59(1.07,19.72)$ \\
\hline $30-34$ & & $4 / 64$ & 6.3 & $2.58(0.47,15.08)$ & $23 / 120$ & 19.2 & $12.96(3.79,44.3)$ & $7.27(1.65,32.04)$ \\
\hline \multicolumn{9}{|l|}{ Marital status } \\
\hline Monogamous & \} & & & & $26 / 204$ & 12.7 & 1 & 1 \\
\hline Polygamous & \} & $6 / 83$ & 7.2 & 1 & $32 / 245$ & 13.1 & $1.03(0.59,1.79)$ & $0.94(0.52,1.7)$ \\
\hline Single & & $4 / 371$ & 1.1 & $0.14(0.03,0.58)$ & $1 / 141$ & 0.7 & $0.05(0.1,0.36)$ & $0.1(0.01,1.0)$ \\
\hline Div/wid & & $0 / 2$ & 0 & 0 & $0 / 15$ & 0 & 0 & 0 \\
\hline \multicolumn{9}{|l|}{ Ethnic group } \\
\hline Jola & & $6 / 313$ & 1.9 & 1 & $40 / 363$ & 11.0 & 1 & 1 \\
\hline Mandinka & & $0 / 71$ & 0 & 0 & $4 / 99$ & 4.0 & $0.34(0.12,0.97)$ & $0.41(0.14,1.21)$ \\
\hline Fula & & $1 / 29$ & 3.3 & $1.76(0.21,15.16)$ & $13 / 52$ & 25.0 & $2.69(1.33,5.47)$ & $2.95(1.36,6.37)$ \\
\hline Other & & $3 / 43$ & 7.0 & $3.84(0.73,18.22)$ & $2 / 91$ & 2.2 & $0.18(0.04,0.7)$ & $0.23(0.05,0.97)$ \\
\hline \multicolumn{9}{|l|}{ Education } \\
\hline None & & $2 / 56$ & 3.5 & 1 & $46 / 343$ & 13.4 & 1 & \\
\hline Islamic & & $5 / 167$ & 3.0 & $0.83(0.14,6.4)$ & $6 / 124$ & 4.8 & $0.33(0.14,0.79)$ & \\
\hline Formal & & $3 / 231$ & 1.3 & $0.36(0.05,3.12)$ & $7 / 138$ & 5.0 & $0.34(0.15,0.78)$ & \\
\hline \multicolumn{9}{|l|}{ Still in school } \\
\hline No & & $9 / 294$ & 3.1 & 1 & $58 / 524$ & 11.1 & 1 & \\
\hline Yes & & $1 / 163$ & 0.6 & $0.2(0.01,1.52)$ & $1 / 81$ & 1.2 & $0.1(0.01,0.74)$ & \\
\hline \multicolumn{9}{|c|}{ Fathered $(\mathrm{M})$ or been pregnant $(\mathrm{F})$} \\
\hline No & & $4 / 374$ & 1.1 & 1 & $8 / 135$ & 5.9 & 1 & 1 \\
\hline Yes & & $6 / 82$ & 7.3 & $7.30(2.01,26.50)$ & $50 / 439$ & 11.4 & $2.04(0.94,4.42)$ & $0.32(0.12,0.86)$ \\
\hline \multicolumn{9}{|c|}{ Sex in past month $\rrbracket$} \\
\hline No & & $4 / 200$ & 2 & 1 & $13 / 164$ & 13.9 & 1 & \\
\hline Yes & & $5 / 80$ & 6.3 & $3.97(0.74,14.95)$ & $46 / 324$ & 14.2 & $1.41(0.72,2.84)$ & \\
\hline
\end{tabular}

${ }^{\star}$ Only those variables that were significant $(p<0.05)$ for one or other of the sexes are shown.

†Because of the lower number of infections among men it was only possible to fit a logistic regression model for women.

$\ddagger$ Adjusted for the other two variables that were included in the final model.

$§$ Participants who had had sex.

Table 7 Risk factors for HSV2*

\begin{tabular}{|c|c|c|c|c|c|c|c|c|}
\hline \multirow[b]{2}{*}{ Risk factor } & & \multicolumn{3}{|l|}{ Men } & \multicolumn{3}{|l|}{ Women } & \multirow[b]{2}{*}{$\begin{array}{l}\text { Adjusted OR }(95 \% \\
\text { CI }) \neq\end{array}$} \\
\hline & & Positive/total & $\%$ positive & Crude OR $(95 \%$ CI $) \dagger$ & Positive/total & $\%$ positive & $\begin{array}{l}\text { Crude OR }(95 \% \\
\text { CI) }\end{array}$ & \\
\hline \multicolumn{9}{|l|}{ Age } \\
\hline $15-19$ & & $5 / 191$ & 2.6 & 1 & $12 / 154$ & 7.8 & 1 & 1 \\
\hline $20-24$ & & $3 / 104$ & 2.9 & $1.1(0.26,4.72)$ & $32 / 153$ & 21.0 & $3.13(1.54,6.34)$ & $1.5(0.64,3.82)$ \\
\hline $25-29$ & & $4 / 75$ & 5.3 & $2.1(0.55,8.03)$ & $63 / 151$ & 41.7 & $8.47(4.33,16.59)$ & $3.99(1.64,9.72)$ \\
\hline $30-34$ & & $10 / 61$ & 16.4 & $7.29(2.39,22.3)$ & $57 / 117$ & 48.7 & $11.24(5.63,22.45)$ & $4.85(1.93,12.19)$ \\
\hline \multicolumn{9}{|l|}{ Marital status } \\
\hline Monogamous & \} & & & & $63 / 196$ & 32.1 & 1 & 1 \\
\hline Polygamous & 3 & $12 / 78$ & 15.0 & 1 & $87 / 234$ & 37.2 & $1.25(0.82,1.9)$ & $1.19(0.75,1.87)$ \\
\hline Single & & $10 / 351$ & 3.0 & $0.16(0.07,0.39)$ & $7 / 129$ & 5.4 & $0.12(0.05,0.29)$ & $0.29(0.09,0.95)$ \\
\hline Wid/div & & $0 / 2$ & 0 & 0 & $7 / 16$ & 43.8 & $1.64(0.52,5.1)$ & $2.15(0.66,6.97)$ \\
\hline \multicolumn{9}{|l|}{ Ethnic group } \\
\hline Jola & & $16 / 294$ & 5.4 & 1 & $122 / 350$ & 34.9 & 1 & 1 \\
\hline Mandinka & & $2 / 66$ & 3.0 & $0.54(0.12,2.42)$ & $17 / 91$ & 18.7 & $0.42(0.24,0.76)$ & $0.31(0.13,0.74)$ \\
\hline Fula & & $1 / 29$ & 3.5 & $0.62(0.08,4.86)$ & $15 / 49$ & 31.9 & $0.88(0.46,1.68)$ & $0.64(0.27,1.55)$ \\
\hline Other & & $3 / 43$ & 7.0 & $1.3(0.36,4.76)$ & $10 / 87$ & 11.5 & $0.24(0.12,0.49)$ & $0.23(0.08,0.61)$ \\
\hline \multicolumn{9}{|l|}{ Education } \\
\hline None & & $4 / 53$ & 7.6 & 1 & $109 / 328$ & 33.2 & 1 & \\
\hline Islamic & & $6 / 158$ & 3.8 & $0.48(0.13,1.78)$ & $26 / 111$ & 23.4 & $0.61(0.37,1.0)$ & \\
\hline Formal & & $12 / 220$ & 5.5 & $0.71(0.22,2.29)$ & $29 / 136$ & 21.3 & $0.54(0.34,0.87)$ & \\
\hline \multicolumn{9}{|c|}{ Currently attending school } \\
\hline No & & $18 / 274$ & 6.6 & 1 & $159 / 497$ & 32.0 & 1 & \\
\hline Yes & & $4 / 158$ & 2.5 & $0.37(0.12,1.11)$ & $5 / 78$ & 6.4 & $0.15(0.06,0.37)$ & \\
\hline \multicolumn{9}{|c|}{ Initiation ceremony in past year } \\
\hline Not attended & & $9 / 199$ & 4.5 & 1 & $74 / 301$ & 24.6 & 1 & \\
\hline Attended & & $5 / 81$ & 6.2 & $1.38(0.45,4.28)$ & $8 / 49$ & 16.3 & $0.6(0.27,1.33)$ & \\
\hline Stayed overnight & & $8 / 151$ & 5.3 & $1.18(0.44,3.14)$ & $82 / 225$ & 36.4 & $1.76(1.26,2.57)$ & \\
\hline \multicolumn{9}{|c|}{ Sex before age 15 (but sexually active) } \\
\hline No & & $7 / 124$ & 5.7 & 1 & $62 / 199$ & 31.2 & 1 & \\
\hline Yes & & $6 / 61$ & 9.8 & $1.82(0.51,6.41)$ & $55 / 177$ & 31.1 & $1(0.63,1.58)$ & \\
\hline No answer & & $4 / 74$ & 5.4 & $0.96(0.23,3.81)$ & $41 / 96$ & 42.7 & $1.65(0.97,2.81)$ & \\
\hline \multicolumn{9}{|l|}{ Sex before marriage } \\
\hline No & & $12 / 218$ & 5.5 & 1 & $148 / 478$ & 31.1 & 1 & \\
\hline Yes & & $10 / 213$ & 4.7 & $0.85(0.36,2.0)$ & $14 / 67$ & 20.9 & $0.59(0.32,1.09)$ & \\
\hline \multicolumn{9}{|c|}{ Fathered $(\mathrm{M})$ or been pregnant $(\mathrm{F})$} \\
\hline No & & $11 / 354$ & 3.1 & 1 & $14 / 124$ & 11.3 & 1 & \\
\hline Yes & & $11 / 77$ & 14.3 & $5.2(2.16,12.48)$ & $147 / 420$ & 35.0 & $4.23(2.34,7.64)$ & \\
\hline \multicolumn{9}{|l|}{ Sex in past month $\mathbb{S}$} \\
\hline No & & $6 / 186$ & 3.0 & 1 & $45 / 156$ & 19.7 & 1 & \\
\hline Yes & & $11 / 72$ & 15.3 & $5.47(1.77,17.46)$ & $112 / 313$ & 35.8 & $1 . .37(0.89,2.13)$ & \\
\hline
\end{tabular}

${ }^{\star}$ Only those variables that were significant $(\mathrm{p}<0.05)$ for one or other of the sexes are shown.

tBecause of the lower number of infections among men it was only possible to fit a logistic regression model for women.

$\ddagger$ Adjusted for the other two variables that were included in the final model.

$§$ Participants who had had sex. 


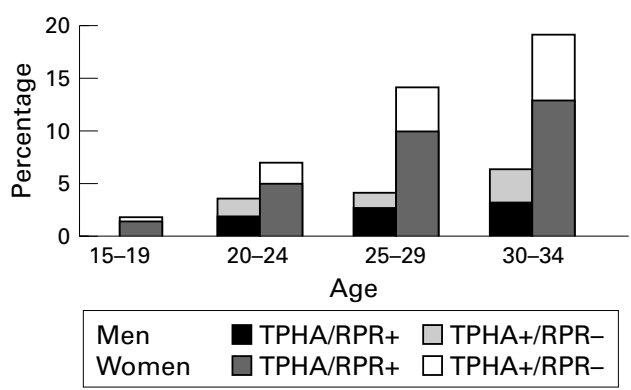

Figure 1 Syphilis serology by sex and age.

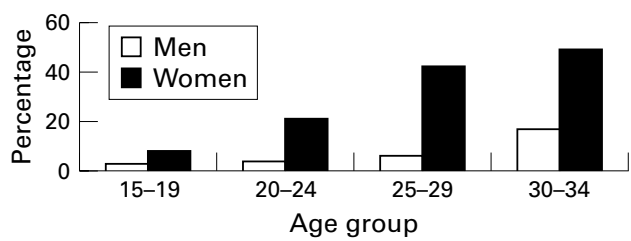

Figure 2 HSV2 serology by sex and age.

higher prevalence of recent untreated syphilis than Jolas. Women currently attending school were at a lower risk and those who reported having sex in the past month were at a higher risk of having recent or untreated syphilis. However, after adjusting for sociodemographic factors, only age ( $\chi^{2}$ test for trend) and ethnicity remained significant.

The prevalence of previous treponemal infection, as shown by TPHA positivity, followed a similar pattern to that of recent or untreated syphilis for both men and women (table 6). Once again the higher number of cases in women permitted a logistic regression model to be fitted, in which age, ethnic group, and marital status remained significant.

HSV2 positivity rose markedly with age in women, while in men it remained low in the younger age groups (fig 2). In men there was no association between HSV2 and educational level or ethnic group (Table 7). Prevalence was higher in those who were married, those who reported fathering a pregnancy, and those who reported sex in the past month. In women HSV2 was higher in those women with no education and in women of the Jola ethnic group. Prevalence was also higher in those who had stayed overnight at an initiation ceremony, those who were married, those who reported sex before age 15, those who had been pregnant, and those who reported sex in the past month. It was lower in women who reported still attending school. After adjustment for possible confounders (women only) only age, ethnic group, and marital status remained significantly associated with HSV2.

None of the STIs were significantly associated with place of birth or having been initiated, after adjusting for marriage. Only $18 \%(161 / 889)$ of those who had had sex had ever used a condom. There was a trend towards fewer infections in the unmarried population who used condoms, but because so few married people had ever used condoms ( $8 \%$, 48/636), and because STI prevalence in the unmarried group who had had sex was so low
$(6 \%, 14 / 226)$, no significant differences were shown.

The proportion of men and women who reported ever having symptoms of STI (dysuria, genital discharge, or genital ulcer) is shown in table 4 . Only $20 \%(31 / 155)$ of women and $53 \%(98 / 186)$ of men attended a clinic with a potential STI symptom, and $58 \%(90 / 155)$ of women and $27 \%(51 / 186)$ of men had not spoken to anyone, including friends or relatives about their problem. Twenty three per cent $(293 / 1247)$ of the participants were identified as needing treatment either because they currently had symptoms which could indicate an STI $(n=53)$ or because of laboratory evidence of active/untreated syphilis or $C$ trachomatis $(\mathrm{n}=247)$ infection. No partners presented at the central clinic with a notification form.

\section{Discussion}

This study has provided much needed data on the prevalence of STIs from a representative sample of both men and women in a rural west African setting. Intensive work with communities before the study helped to ensure a relatively high participation rate, and relatively few refusals for blood and urine samples. The involvement of government officials in the sensitisation process was a critical factor. Considering response rates there was some indication that the Jola and Fula ethnic groups were slightly underrepresented for women but this would be unlikely to introduce a large bias in prevalences. The lower proportion of older men resident in the villages may indicate substantial out migration to the urban area. There were some restrictions to the sexual behaviour data that could be asked-for example, questions to women about extramarital partners. Although there was a high response rate to the questions on sexual behaviour the number of "virgins" who had positive laboratory results suggests a lack of validity in the responses to the questionnaire. While infection with HIV or other STIs does not necessarily indicate risky behaviour ${ }^{11}$ (for example, it may indicate risky behaviour by a spouse), these concerns about validity show that it is necessary to include a biological marker of sexual exposure in this area.

The prevalence of HSV2 seen in our study is consistent with other studies in the Gambia ${ }^{17}$ and west Africa ${ }^{13}$ but lower than prevalences found in east and southern Africa. ${ }^{13}{ }^{25}$ However, the tests used to detect HSV2 differ from study to study so prevalences are not strictly comparable. $^{26}$ Similarly, the prevalence of syphilis was consistent with other studies in the Gambia and west Africa ${ }^{17}{ }^{27}$ but not as high as community surveys from other parts of the continent. ${ }^{1328}$ It has been noted elsewhere in the Gambia that Fula women have high rates of positive syphilis serology ${ }^{17}$ and that this is not always associated with adverse pregnancy outcome. ${ }^{29}$ More research is needed to understand the high prevalence of TPHA/RPR among the Fula ethnic group. The prevalence of chlamydial infection assessed by PCR was very low, 
again consistent with other studies in the area. ${ }^{17} 13$

HSV2 and syphilis are both ulcerative STIs which are known to be important cofactors in the transmission of HIV. The high prevalences found, especially in the older age groups of women, are therefore a cause for concern. Possibilities for enhancing STI control in the Gambia include antenatal screening which could be an effective strategy for active case finding of syphilis. Currently the resources are not available to carry this out in most facilities in the Gambia, although it is government policy. In the main clinic in the study area, screening is currently only available to mothers who have previously had an adverse pregnancy outcome. Our study suggests that even if resources are scarce screening with contact tracing should be introduced at least for the older women. The only affordable prospect for control of HSV2 is through primary prevention-either through the adoption of safer sex or, in the future, a vaccine.

In our study while women had higher prevalences of STIs than men only a fifth of women compared with half of men who experienced a symptom potentially related to an STI sought treatment from health services. Although perceived symptoms may not be a reliable indicator of infection, ${ }^{21}$ this indicates that improved access to services is needed especially for women. The fact that half of single men and a fifth of single women had had sex indicates that services for young, single people should not be neglected.

HSV2 and syphilis prevalence increased with age. This is to be expected as HSV2 and TPHA seropositivity are believed to be lifelong. They were also more common in married participants, probably because of regular and frequent unprotected intercourse with a possibly infected spouse. Questions on extramarital sex and numbers of lifetime or recent partners, known risk factors for STIs/HIV, were considered unacceptable so were not included in this study. However, since HSV2 has been shown to be associated with number of lifetime partners ${ }^{1325}$ it was surprising that there was no association between polygamous marriage and HSV2 prevalence in women in our study. It is possible that some women may wait until marriage before having extramarital relationships as there is then nothing to fear from pregnancy. This would dilute the effect of polygyny as a risk factor for HSV2. Other sexual behaviour risk factors which were associated with STIs in the bivariate analysis were no longer significant after adjusting for sociodemographic variables.

In Senegal reduced alcohol consumption, adherence to strong Islamic social values, and the early mobilisation of society against HIV, have also been suggested as factors that have reduced the spread of HIV. ${ }^{30}$ However, data from the sentinel sites in southern Senegal (currently affected by conflict) still showed an increasing trend in HIV prevalence. The population surveyed in this study have close links with the population of southern Senegal. Our study suggests that in the Gambia (where health promotion and STI treatment are not as established as in Senegal) there is a risk of increasing HIV prevalence.

\section{Conclusions}

This survey provides valuable data on HSV2 and syphilis prevalence among a large representative sample of men and women in rural west Africa. The prevalence of HSV2 and syphilis described are a cause for concern. In a setting where HIV1 prevalence remains low this indicates an urgent need for STI control and behaviour change programmes to prevent an HIV epidemic. While women were disproportionately affected by the STIs in our survey they were also much less likely to seek treatment for an STI related symptom than men. Comparison of reported sexual behaviour against serology confirms doubts about the validity of sexual behaviour data collected using structured questionnaires in this setting. This supports the potential contribution of biological markers in the evaluation of behaviour change programmes.

Funding for this study was provided by the Medical Research Council. The Stepping Stones-Gambia project is a collaboration between the government of the Gambia Department of State for Health, the Gambia Family Planning Association, ActionAid the Gambia, the Medical Research Council, and a local mission the Gambia, the Medical Research Council, and a local mission
clinic. The following were all essential to the success of the work clinic. The following were all essential to the success of the work
presented here: Stepping Stones Steering Committee: Dr Gaye, Dr presented here: Stepping Stones Steering Committee: Dr Gaye, Dr
Gassama, Yankuba Dibba, Sylvia Wachuku-King, Professor McAdam, Dr Gisela Schneider; Project Management Committee: McAdam, Dr Gisela Schneider; Project Management Committee:
Ebrima Sowe, Mariama Jallow, Mutar Jammeh; Supervisors: Ebrima Sowe, Mariama Jallow, Mutar Jammeh; Supervisors:
Mafugi Dibba, Aveika Akum; Kunle Okunoye. Graham Hart for advice; Field workers: Alpha Jawo, Lamin Gibba, Haddiatou Jallow, Emily Loppy; Laboratory staff: Edward Demba, Nkaye Kanyi, William Bidwell, Fatou Secka, Mohammed Aiyegbo; Drivers: Assan Jallow, Lamin Touray, Abdoulie Chongan; Sensitisation: Abie Khan, the Alkalo of Killy, The MP of Fonyii Bintang FaAnsu Sanneh, Assan Jobarteh; the people of all the villages involved.

Contributors: MS and LM wrote the paper and, together with MvdS, were responsible for concept and design, and statistical analysis; BW managed sample collection and analysis; KP developed the questionnaire and together with MvdS supervised the fieldwork; SC coordinated the government's support and sensitisation of the participants; KMcA was on the steering and sensitisation of the participants; KMcA was on the steering collaborated with the above to finalise the manuscript for publication.

1 UNAIDS. Report on the global HIVIAIDS epidemic. Geneva: UNAIDS, 2000

2 Weiss HA, Quigley MA, Hayes RJ. Male circumcision and risk of HIV infection in sub-Saharan Africa: a systematic review and meta-analysis. AIDS 2000;14:2361-70.

3 UNAIDS. Epidemiological fact sheet on HIV, AIDS and sexually transmitted Infections. Geneva: UNAIDS, update 2000 .

4 Anderson RM, May RM, Boily MC, et al. The spread of HIV-1 in Africa: sexual contact patterns and the predicted demographic impact of AIDS. Nature 1991;352:581-9.

5 Grosskurth $\mathrm{H}$, Mosha F, Todd J, et al. Impact of improved treatment of sexually transmitted diseases on HIV infection in rural Tanzania: randomised controlled trial. Lancet 1995;346:530-6.

6 Family Health International and AIDS Control and Prevention. Final report for the AIDSCAP programme in Senegal. Final report for the AIDS
Arlington, Virginia, 1998.

7 Triangulation of biological markers and quantitative and qualitative responses in sexual behaviour research with adolescents in rural Tanzania. XIII International Conference on AIDS, Durban 7 Sep 2000

8 Huygens P, Kajura E, Seeley J, et al. Rethinking methods for the study of sexual behaviour. Soc Sci Med 1996;42:22131 .

9 Skramstad H. Prostitute as metaphor in gender construction; a Gambian setting. 1993. Working Paper, Development Research and Action Programme, Chr. Michelson Institute, Dept of Social science and Development.

10 Pickering $\mathrm{H}$. Asking questions on sexual behaviour...testing methods from the social sciences. Health Policy Planning 1988;3:237-44

11 Fishbein M, Jarvis B. Failure to find a behavioural surrogate for STD incidence-what does it really mean? Sex Transm Dis $2001 ; 27: 452-5$.

12 Grosskurth H, Gray R, Hayes R, et al. Control of sexually transmitted diseases for HIV-1 prevention:understanding the implications of the Mwanza and Rakai trials. Lancet 2000;355:1981-7. 
13 Weiss $\mathrm{H}$. HSV-2 seroprevalence and association with HIV infection in four urban African populations. Study Group on the Heterogeneity of HIV Epidemics in African Cities
Presented at the 13th meeting of the international Society Presented at the 13th meeting of the international Society
for STD Research, 11-14 July 1999. Denver, Colorado, for STD Resea

14 Auvert B, Ballard R, Campbell C, et al. HIV infection among youth in a South African mining town is associated with herpes simplex virus-2 seropositivity and sexual behaviour. AIDS 2001;15:885-98.

15 Nelson KE, Eiumtrakul S, Celentano D, et al. The association of herpes simplex virus type 2 (HSV-2), Haemophilus ducreyi, and syphilis with HIV infection in young men in northern Thailand. f Acquir Immune Defic Syndr Hum Retrovirol 1997;16:293-300.

16 McFarland W, Gwanzura L, Bassett MT, et al. Prevalence and incidence of herpes simplex virus type 2 infection among male Zimbabwean factory workers. F Infect Dis 1999; 180:1459-65.

17 Walraven G, Scherf C, West B, et al. The burden of reproductive-organ disease in women in rural Gambia, reproductive-organ disease in women
West Africa. Lancet 2001;357:1161-7.

18 Whittle H, Yamuah LK, O'Donovan D, et al. HIV-1 and Whittle H, Yamuah LK, O'Donovan D, et al. HIV-1 and HIV-2 infection in pregnant women i
factors. Int Conf AIDS 1998;12:373-4.

19 Morison L, Scherf C, Ekpo G, et al. Female genital cutting and the reproductive health of women in rural Gambia: a community based study. Trop Med Int Health 2001;6:64353.

20 Paine K, Hart G, Jawo M, et al. "Before we were sleeping, now we are awake": preliminary evaluation of a bia (submitted).

21 Hawkes S, Morison L, Foster S, et al. Managing reproductive tract infections in women in low -income, low prevalencesituations: an assessment of syndromic management in Matlab, Bangladesh. Lancet 1999;354:1176-1781

22 Bailey RL, Hampton TJ, Hayes LJ, et al. Polymerase chain reaction for the detection of ocular chlamydial infection in trachoma-endemic communities. F Infect Dis 1994;170: 709-12.

23 Marsden HS, MacAulay K, Murray J, et al. Identification of an immunodominant sequential epitope in glycoprotein $\mathrm{G}$ of herpes simplex virus type 2 that is useful for serotype-specific diagnosis. f Med Virol 1998;56:79-84.

24 Report of a WHO Study group. Management of patients with sexually transmitted diseases. Geneva: WHO, 1991.

25 Obasi A, Mosha F, Quigley M, et al. Antibody to herpes simplex virus type 2 as a marker of sexual risk behavior in rural Tanzania. $\mathcal{F}$ Infect Dis 1999;179:16-24.

26 An evaluation of four commercial $\mathrm{HSV}-2 \mathrm{IgG}$ antibody assays. Presented at the 13th meeting of the international Society for STD Research, 11-14 July 1999. Denver, Colorado, USA, 2000.

27 Bertherat E, Georges-Courbot MC, Nabias R, et al. Seroprevalence of four sexually transmitted diseases in a semi-urban population of Gabon. Int F STD AIDS 1998;9: 31-6.

28 Colvin M, Sharp B. Sexually transmitted infections and HIV in a rural community in the Lesotho highlands. Sex Transm Inf 2000;76:39-42.

29 Greenwood AM, D'Alessandro U, Sisay F, et al. Treponemal infection and the outcome of pregnancy in a rural area of the Gambia, west Africa [see comments]. F Infect Dis 1992;166:842-6.

30 Meda N, Ndoye I, M'Boup S, et al. Low and stable HIV infection rates in Senegal: natural course of the epidemic or evidence for success of prevention? AIDS 1999;13:1397405. 